\title{
Synergistic Effect of KI on Corrosion Inhibition of Mild Steel by Polynuclear Schiff Base in Sulphuric Acid
}

\author{
K. S. Shaju, K. Joby Thomas, Vinod P. Raphael, and Aby Paul \\ Research Division, Department of Chemistry, St. Thomas' College, University of Calicut, Thrissur, Kerala, India \\ Correspondence should be addressed to K. Joby Thomas, drjobythomask@gmail.com
}

Received 17 October 2012; Accepted 1 November 2012

Academic Editors: A. Y. El-Etre and H. Sarpoolaky

Copyright (๑) 2012 K. S. Shaju et al. This is an open access article distributed under the Creative Commons Attribution License, which permits unrestricted use, distribution, and reproduction in any medium, provided the original work is properly cited.

Synergistic effect of KI on the corrosion inhibition efficiency of polynuclear Schiff base, anthracene-9(10H)-one-3-aminopropanoic acid (A9O3AP), on mild steel (MS) in $0.5 \mathrm{M}$ sulphuric acid solution has been investigated using weight loss measurements, electrochemical impedance spectroscopy (EIS), and potentiodynamic polarization studies. The results show that inhibition efficiencies on MS increase with increase in concentration of the inhibitor and enhancement in inhibition efficiency was observed on addition of potassium iodide due to synergism. The adsorptions, of inhibitor and inhibitor + KI on the surfaces of the corroding metal obey Freundlich and Langmuir isotherms, respectively. Polarization studies revealed that A9O3AP acts as a mixed type inhibitor. Thermodynamic parameters $\left(\mathrm{K}_{\mathrm{ads}} ; \Delta G_{\mathrm{ads}}^{0}\right)$ were calculated using the adsorption isotherms. A probable synergismtic mechanism is proposed.

\section{Introduction}

The use of certain organic compounds as inhibitors is the most practical method to prevent corrosion of the mild steel (MS) in acidic media $[1,2]$. Compounds with $\pi$ bonds generally exhibit good inhibitive properties due to interaction of $\pi$-orbital with the metal surface [3]. Schiff bases are organic molecules possessing azomethine linkage and many of them act as effective potential corrosion inhibitors [4-7]. The addition of halide ions to sulphuric acid solutions containing organic inhibitors has been found to stabilize the adsorption of organic cations, leading to improved inhibition efficiency. The synergistic effect of the halides have been observed to increase in the order $\mathrm{Cl}^{-}<$ $\mathrm{Br}^{-}<\mathrm{I}^{-}$. Due to large size and ease of polarizability, iodide $\left(\mathrm{I}^{-}\right)$shows the highest synergistic effect [8-11].

The present investigation was undertaken to examine the corrosion inhibition behavior and synergism mechanism $[12,13]$ with $\mathrm{I}^{-}$of a novel polynuclear Schiff base (A9O3AP) derived from anthracene-9 $(10 \mathrm{H})$-one and 3aminopropanoic acid in $0.5 \mathrm{M} \mathrm{H}_{2} \mathrm{SO}_{4}$ solution on $\mathrm{MS}$ at $303 \mathrm{~K}$.

\section{Experimental}

2.1. Inhibitor. Polynuclear Schiff base (A9O3AP) was obtained by the condensation of equimolar mixture of anthracene-9(10H)-one and 3-aminopropanoic acid in ethanol. The reaction mixture was refluxed for 5 hours, cooled by keeping overnight to obtain yellow coloured compound, filtered, washed, and dried. Figure 1 shows the molecular structure of polynuclear Schiff base A9O3AP. Anal.calcd for $\mathrm{C}_{17} \mathrm{H}_{15} \mathrm{NO}_{2}$ : C, 76.88; H, 5.65; N, 5.28\%. Found. C, 75.96; H, 6.13; N, 4.95\%; m.p. $=240^{\circ} \mathrm{C}$; IR $(\mathrm{KBr})$ : $\nu_{\mathrm{C}=\mathrm{N}}=1559 \mathrm{~cm}^{-1}, \nu_{\mathrm{COOH}}=3067 \mathrm{~cm}^{-1} \cdot{ }^{1} \mathrm{Hnmr}: \delta_{\mathrm{COOH}}$ $12.19,{ }^{13} \mathrm{Cnmr}: \delta_{\mathrm{COOH}}=169.93, \delta_{\mathrm{C}=\mathrm{N}}=150.8 \mathrm{ppm}$.

2.2. Solutions. The aggressive solution of $0.5 \mathrm{M} \mathrm{H}_{2} \mathrm{SO}_{4}$ was prepared by the dilution of A.R grade $98 \%$ of $\mathrm{H}_{2} \mathrm{SO}_{4}$ (Merck) with deionized water. Inhibitor solutions were prepared in the range, $0.2 \mathrm{mM}-1 \mathrm{mM}$ concentrations.

2.3. Weight Loss Measurements. Mild steel specimens of dimension $1.5 \times 2 \times 0.1 \mathrm{~cm}$ (composition: C, $0.5 \%$; Mn, $0.07 \%$; P, 0.02\%; S, 0.015\%; Si, 0.02\%, and rest Fe) were cut 


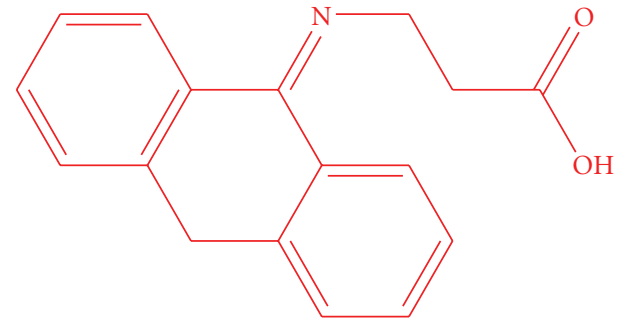

Figure 1: Molecular structure of A9O3AP.

and abraded with various grades of silicon carbide papers $(200,400,600,800,1000,1200$, and 2000). The exact area and thickness of each coupon were measured and washed with soap water. Specimens were then degreased again with acetone and finally dried. After weighing, specimens were immersed in $50 \mathrm{~mL}$ acid solutions (naturally aerated) at $30^{\circ} \mathrm{C}$ in the absence and presence of the inhibitor (A9O3AP) and $\mathrm{I}^{-}$using hooks and fishing lines. Weight loss of metal specimens was noted after $24 \mathrm{~h}$. The corrosion rate $(\nu)$ and the percentage of inhibition efficiency $\left(\eta_{w} \%\right)$ were calculated by the following equations [14-16]:

$$
\begin{gathered}
\nu=\frac{W}{S t}, \\
\eta_{w} \%=\frac{\nu_{0}-v}{\nu_{0}} \times 100,
\end{gathered}
$$

where $W$ is the weight loss $(g)$ of coupon, $S$ is the total area $\left(\mathrm{cm}^{2}\right)$ of specimens, $t$ is the time of treatment $(24 \mathrm{hrs}), \nu_{0}$ and $v$ are the corrosion rates of uninhibited and inhibited specimens, respectively.

2.4. Electrochemical Impedance Spectroscopy (EIS). The EIS measurements were performed in a three electrode assembly. Saturated calomel electrode (SCE) was used as the reference electrode. Platinum electrode having $1 \mathrm{~cm}^{2}$ area was taken as counter electrode. Metal specimens with an exposed area of $1 \mathrm{~cm}^{2}$ were used as the working electrode. The EIS experiments were carried out on an Ivium compactstat-e electrochemical system. $0.5 \mathrm{M} \mathrm{H}_{2} \mathrm{SO}_{4}$ (no deaeration, no stirring) was taken as the electrolyte and the working area of the metal specimens were exposed to the electrolyte for $1 \mathrm{~h}$ prior to the measurement. EIS measurements were performed at constant potential (OCP) in the frequency range from $1 \mathrm{KHz}$ to $100 \mathrm{mHz}$ with amplitude of $10 \mathrm{mV}$ as excitation signal. The percentage of inhibitions from impedance measurements were calculated using charge transfer resistance values by the following expression [17]:

$$
\eta_{\mathrm{EIS}} \%=\frac{R_{\mathrm{ct}}-R_{\mathrm{ct}}^{\prime}}{R_{\mathrm{ct}}} \times 100,
$$

where $R_{\mathrm{ct}}$ and $R_{\mathrm{ct}}^{\prime}$ are the charge transfer resistances of working electrode with and without inhibitor, respectively.

2.5. Potentiodynamic Polarization. Electrochemical polarization studies of MS specimens in $0.5 \mathrm{M} \mathrm{H}_{2} \mathrm{SO}_{4}$ with and without inhibitor and KI were performed by recording anodic and cathodic potentiodynamic polarization curves. Polarization plots were obtained in the electrode potential range from -100 to $+100 \mathrm{mV}$ Vs equilibrium potential at a scan rate of $1 \mathrm{mV} / \mathrm{sec}$. Tafel polarization analyses were done by extrapolating anodic and cathodic curves to obtain corrosion current densities $\left(I_{\text {corr }}\right)$. The percentage of inhibition efficiency $\left(\eta_{\text {pol\% }}\right)$ was evaluated from the measured $I_{\text {corr }}$ values using the following relation [18]:

$$
\eta_{\mathrm{pol}} \%=\frac{I_{\text {corr }}-I_{\text {corr }}^{\prime}}{I_{\text {corr }}} \times 100,
$$

where $I_{\text {corr }}$ and $I_{\text {corr }}^{\prime}$ are the corrosion current densities of the exposed area of the working electrode in the absence and presence of inhibitor.

\section{Results and Discussion}

3.1. Weight Loss Measurements. Weight loss of MS specimens in $0.5 \mathrm{M} \mathrm{H}_{2} \mathrm{SO}_{4}$ at $30^{\circ} \mathrm{C}$ was determined at $24 \mathrm{~h}$ in the presence of various concentrations of inhibitor (A9O3AP) and inhibitor $+\mathrm{KI}$. The corrosion rates, inhibition efficiencies, and surface coverage $(\theta)$ in the presence of inhibitor and inhibitor + $0.2 \mathrm{mM}$ KI for MS specimens for the period of $24 \mathrm{~h}$ are shown in the Table 1.

From Table 1, it is clear that the corrosion rate markedly decreased with inhibitor concentration from 0 to $0.2 \mathrm{mM}$. Beyond this concentration, corrosion rate showed a gradual decrease. This response is due to the fact that the surface coverage $(\theta)$ of the inhibitor molecules on the metal through adsorption increases with increase in concentration. The inhibitor + KI system showed similar trend. From Table 1 it is also evident that the inhibition efficiency increased with increase in concentration. At the inhibitor concentration of $1.0 \mathrm{mM}$, the maximum $\eta_{W} \%$ was 43.75 , which shows that individual inhibitor cannot protect much effectively the corrosion of $\mathrm{MS}$ in $\mathrm{H}_{2} \mathrm{SO}_{4}$. Table 1 also shows the values of $\eta_{W} \%$ for a constant $\mathrm{KI}$ concentration $(0.2 \mathrm{mM})$ and changing inhibitor concentration in $0.5 \mathrm{M} \mathrm{H}_{2} \mathrm{SO}_{4}$ solution. Compared with the inhibition efficiency values of inhibitor (without KI), it was found that the combination of inhibitor and $0.2 \mathrm{mM}$ KI has better inhibition efficiency for all studied inhibitor concentrations.

3.2. Comparison of Inhibition Efficiency of Schiff Base with Its Parent Amine. To compare the inhibition efficiencies of Schiff base and parent amine (3-aminopropanoic acid), weight loss measurements of MS specimens were performed in $0.5 \mathrm{M} \mathrm{H}_{2} \mathrm{SO}_{4}$ at $30^{\circ} \mathrm{C}$. The percentage of corrosion inhibition efficiencies obtained for Schiff base and parent amine on MS are represented in the Figure 2. The inhibition efficiency of the Schiff base A9O3AP was markedly higher than that of 3-aminopropanoic acid for the studied concentrations. This investigation clearly establishes the role of azomethine linkage $(C=N)$ present in the Schiff base which actively participate in the corrosion inhibition mechanism.

3.3. Adsorption Isotherm and Free Energy of Adsorption. The mechanism of adsorption and the surface behavior of 
TABle 1: Calculated values of inhibition efficiency ( $\left.\eta_{W} \%\right)$ for MS corrosion in $0.5 \mathrm{M} \mathrm{H}_{2} \mathrm{SO}_{4}$ for different systems at $30^{\circ} \mathrm{C}$ from weight loss measurements.

\begin{tabular}{lccc}
\hline Systems/concentrations & $\begin{array}{c}\text { Corrosion rate } \\
(\mathrm{mm} / \mathrm{y})\end{array}$ & $\begin{array}{c}\text { Inhibition } \\
\text { efficiency } \\
\left(\eta_{W} \%\right)\end{array}$ & $\theta$ \\
\hline Blank & 24.01 & - & - \\
Blank + 0.2 mM KI & 19.40 & 19.16 & 0.19 \\
$0.2 \mathrm{mM}$ A9O3AP & 18.06 & 24.77 & 0.25 \\
$0.4 \mathrm{mM}$ A9O3AP & 17.19 & 28.38 & 0.28 \\
$0.6 \mathrm{mM}$ A9O3AP & 15.96 & 33.54 & 0.34 \\
$0.8 \mathrm{mM}$ A9O3AP & 14.58 & 39.25 & 0.39 \\
$1.0 \mathrm{mM}$ A9O3AP & 13.50 & 43.75 & 0.44 \\
$0.2 \mathrm{mM}$ A9O3AP + 0.2 mM KI & 10.88 & 54.67 & 0.55 \\
$0.4 \mathrm{mM}$ A9O3AP + 0.2 mM KI & 10.22 & 57.41 & 0.57 \\
$0.6 \mathrm{mM}$ A9O3AP + 0.2 mM KI & 9.08 & 62.16 & 0.62 \\
$0.8 \mathrm{mM}$ A9O3AP + 0.2 mM KI & 6.84 & 71.49 & 0.71 \\
$1.0 \mathrm{mM}$ A9O3AP + 0.2 mM KI & 5.58 & 76.75 & 0.77 \\
\hline
\end{tabular}

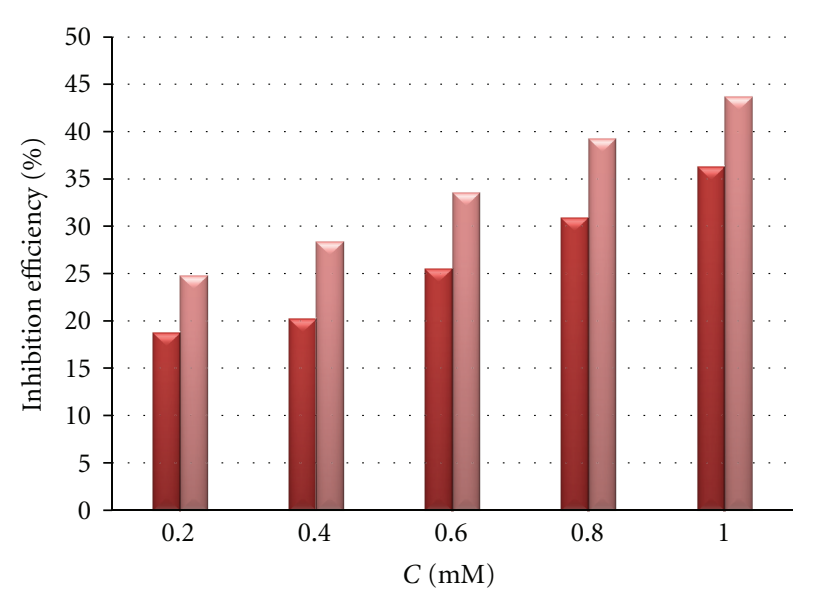

Series 1: Parent amine

Series 2: Schiff base

FIgURe 2: Comparison of inhibition efficiency of Schiff base and parent amine in $0.5 \mathrm{M} \mathrm{H}_{2} \mathrm{SO}_{4}$ at $24 \mathrm{~h}$.

organic molecules can be easily viewed through adsorption isotherms. Different models of adsorption isotherms considered are Langmiur, Temkin, Frumkin, and Freundlich isotherms. For the evaluation of thermodynamic parameters it is necessary to determine the best fit isotherm with the aid of correlation coefficient $\left(R^{2}\right)$. Among the isotherms mentioned above, the best description of the adsorption behavior of A9O3AP and A9O3AP + KI on MS specimens in $0.5 \mathrm{M} \mathrm{H}_{2} \mathrm{SO}_{4}$ was Freundlich and Langmiur adsorption isotherms, respectively. These models are expressed as [19]

Freundlich adsorption isotherm:

$$
\theta=K_{\mathrm{ads}} C,
$$

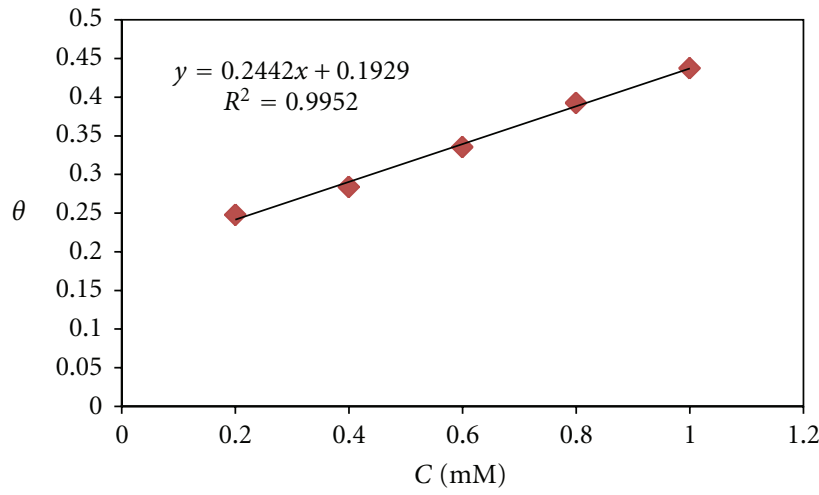

FIGURE 3: Freundlich adsorption isotherm for adsorption of A9O3AP on MS surface in $0.5 \mathrm{M} \mathrm{H}_{2} \mathrm{SO}_{4}$ at $30^{\circ} \mathrm{C}$ for $24 \mathrm{~h}$.

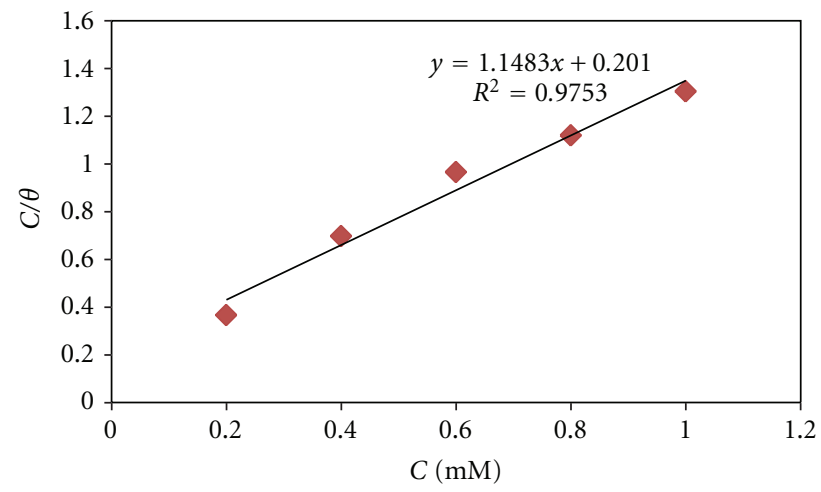

FIGURE 4: Langmuir adsorption isotherm for adsorption of $\mathrm{A} 9 \mathrm{O} 3 \mathrm{AP}+\mathrm{KI}$ on MS surface in $0.5 \mathrm{M} \mathrm{H}_{2} \mathrm{SO}_{4}$ at $30^{\circ} \mathrm{C}$ for $24 \mathrm{~h}$.

Langmiur adsorption isotherm:

$$
\frac{C}{\theta}=\frac{1}{K_{\mathrm{ads}}}+C,
$$

where $C$ is the concentration of the inhibitor, $\theta$ is the fractional surface coverage and $K_{\mathrm{ads}}$ is the adsorption equilibrium constant. Figures 3 and 4 represent the adsorption plots of A9O3AP and A9O3AP + KI obtained by the weight loss measurements of MS steel specimens in $0.5 \mathrm{M} \mathrm{H}_{2} \mathrm{SO}_{4}$ at $30^{\circ} \mathrm{C}$ for $24 \mathrm{~h}$, respectively.

The adsorption equilibrium constant $K_{\text {ads }}$ is related to the standard free energy of adsorption $\Delta G_{\text {ads }}^{0}$, by

$$
\Delta G_{\mathrm{ads}}^{0}=-R T \ln \left(55.5 K_{\mathrm{ads}}\right),
$$

where 55.5 is the molar concentration of water, $R$ is the universal gas constant, and $T$ is the temperature in Kelvin [20]. Table 2 explores thermodynamic parameters obtained from weight loss measurements of MS in $0.5 \mathrm{M} \mathrm{H}_{2} \mathrm{SO}_{4}$ at $30^{\circ} \mathrm{C}$ for $24 \mathrm{~h} . \Delta G_{\text {ads }}^{0}$ for A9O3AP and A9O3AP + KI on MS showed negative values indicating the spontaneity of the process. The value of $\Delta G_{\text {ads }}^{0}$ upto $-20 \mathrm{~kJ} \mathrm{~mol}^{-1}$ is an indication of the electrostatic interaction of the charged molecule and the charged surface of the metal (physisorption) while $\Delta G_{\mathrm{ads}}^{0}$ is more negative than $-40 \mathrm{~kJ}$ implies 
TABLE 2: Thermodynamic parameters obtained from weight loss studies.

\begin{tabular}{lccc}
\hline MS in & Isotherm & $K_{\text {ads }}$ & $\begin{array}{c}\Delta G_{\text {ads }}^{0} \\
(\mathrm{~kJ} / \mathrm{mol})\end{array}$ \\
\hline A9O3AP & Freundlich & 244 & -23.9 \\
A9O3AP + KI & Langmiur & 871 & -27.1 \\
\hline
\end{tabular}

TABLE 3: Synergism parameter $\left(S_{\theta}\right)$ for different concentrations of inhibitor in combination with $0.2 \mathrm{mM} \mathrm{KI}$.

\begin{tabular}{lc}
\hline Concentration & Synergism parameter, $S_{\theta}$ \\
\hline $0.2 \mathrm{mM}$ & 1.34 \\
$0.4 \mathrm{mM}$ & 1.36 \\
$0.6 \mathrm{mM}$ & 1.42 \\
$0.8 \mathrm{mM}$ & 1.73 \\
$1.0 \mathrm{mM}$ & 1.96 \\
\hline
\end{tabular}

that inhibitor molecules are adsorbed strongly on the metal surface through coordinate type bond (chemisorption) [21, 22]. In the present investigation, A9O3AP and A9O3AP + KI molecules showed $\Delta G_{\text {ads }}^{0}-23.9$ and -27.1 , respectively, for MS specimens suggesting that the adsorption of inhibitor involves both electrostatic and chemical interactions.

3.4. Synergistic Effect. The addition of KI drastically increases the $\eta_{W} \%$ values; for instance, $\eta_{W} \%$ of individual $0.2 \mathrm{mM}$ is $19.16 \%$. From Table 1 it is clear that $\eta_{W} \%$ for KI in combination with inhibitor is higher than the summation of $\eta_{W} \%$ for single KI and single inhibitor, which is synergistic in nature. Aramaki and Hackerman [23] calculated the synergism parameter $S_{\theta}$ using the following equation:

$$
S_{\theta}=\frac{1-\theta_{1+2}}{1-\theta_{1+2}^{\prime}}
$$

where $\theta_{1+2}=\left(\theta_{1}+\theta_{2}\right)-\left(\theta_{1} \theta_{2}\right) ; \theta_{1}=$ surface coverage by anion; $\theta_{2}=$ surface coverage by cation; $\theta_{1+2}^{\prime}=$ measured surface coverage by both anion and cation. $S_{\theta}$ approaches unity when there are no interactions between the inhibitor compounds, while $S_{\theta}>1$ points to a synergistic effect; in the case of $S_{\theta}<1$, the antagonistic interaction prevails. The values of the synergism parameter for the various concentrations of A9O3AP studied from the gravimetric analysis are presented in Table 3 .

All values shown in this table are greater than unity. This is an indication that the enhanced inhibition efficiency resulting from the addition of iodide ions to A9O3AP is synergistic in nature [24].

3.5. EIS Measurements. The corrosion response of MS in $0.5 \mathrm{M} \mathrm{H}_{2} \mathrm{SO}_{4}$ in the presence of various concentrations of inhibitor and inhibitor + KI systems has been investigated using Electrochemical Impedance Spectroscopy at $30^{\circ} \mathrm{C}$. Figures 5 and 6 represent the Nyquist plots of MS specimens in $0.5 \mathrm{M} \mathrm{H}_{2} \mathrm{SO}_{4}$ in the presence of various concentrations of inhibitor and inhibitor + KI, respectively. It is evident from the plots that the impedance response of metal specimens has

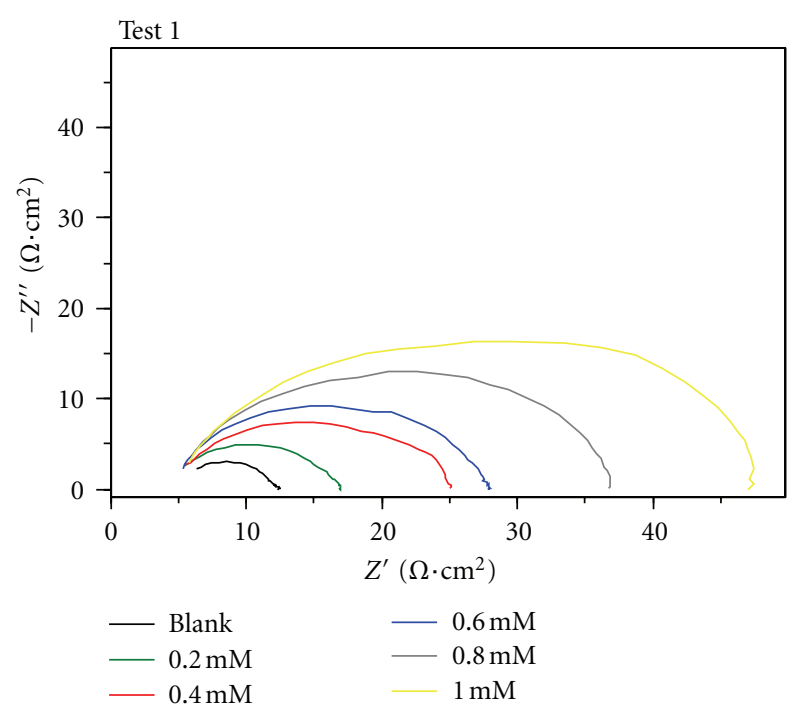

FIgURe 5: Nyquist plots for MS specimens in $0.5 \mathrm{M} \mathrm{H}_{2} \mathrm{SO}_{4}$.

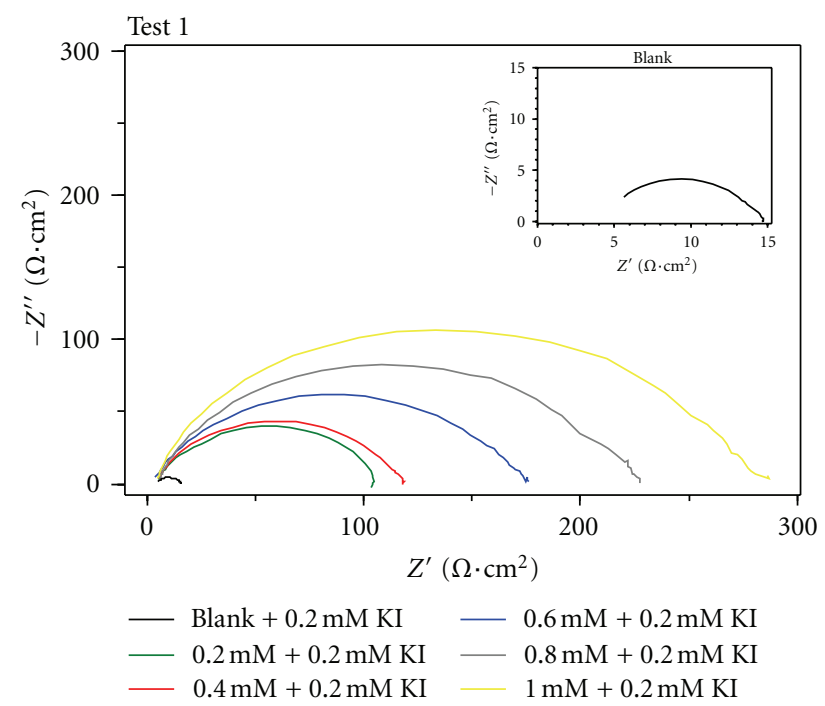

Figure 6: Nyquist plots (synergistic effect) for MS specimens in $0.5 \mathrm{M} \mathrm{H}_{2} \mathrm{SO}_{4}$.

marked difference in the presence and absence of the KI with inhibitor A9O3AP.

Impedance behaviour can be well explained by pure electric models that could verify and enable to calculate numerical values corresponding to the physical and chemical properties of electrochemical system under examination [25]. The simple equivalent circuit that fit to many electrochemical systems composed of a double layer capacitance, $R_{s}$ and $R_{\mathrm{ct}}[26,27]$. To reduce the effects due to surface irregularities of metal, constant phase element (CPE) is introduced into the circuit instead of a pure double layer capacitance which gives more accurate fit as shown in the Figure 7 [28]. 


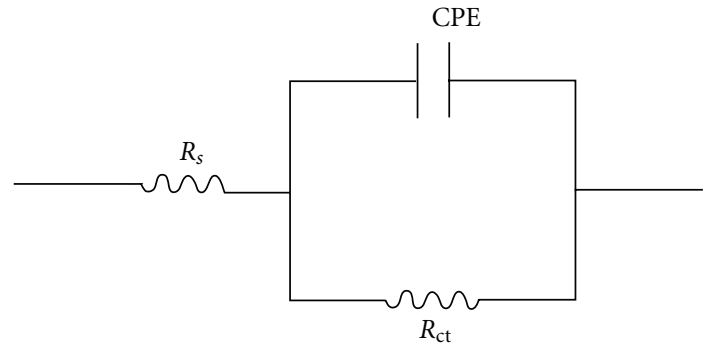

FIGURE 7: Equivalent circuit fitting for EIS measurements.

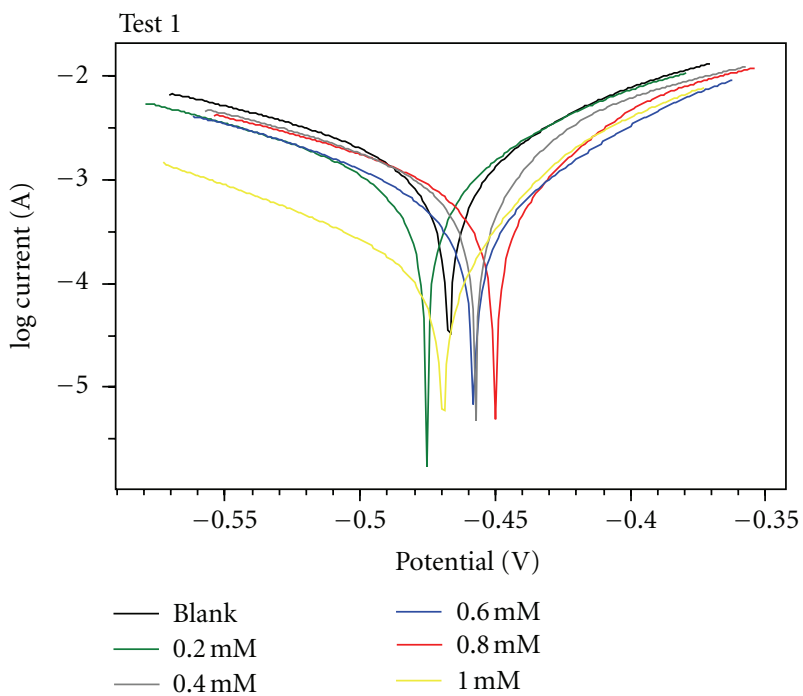

Figure 8: Tafel plots of MS specimens in $0.5 \mathrm{M} \mathrm{H}_{2} \mathrm{SO}_{4}$ at $30^{\circ} \mathrm{C}$, with and without inhibitor.

The impedance of CPE can be expressed as

$$
Z_{\mathrm{CPE}}=\frac{1}{Y_{0}(j \omega)^{n}},
$$

where $Y_{0}$ is the magnitude of CPE, $n$ is the exponent (phase shift), $\omega$ is the angular frequency, and $j$ is the imaginary unit. CPE may be resistance, capacitance, and inductance depending upon the values of $n$ [29]. In all experiments the observed value of $n$ ranges between 0.75 and 1.0, suggesting the capacitive response of CPE. The EIS parameters such as $R_{\mathrm{ct}}, R_{s}$, and CPE and the calculated values of percentage of inhibition $\left(\eta_{\mathrm{EIS}}\right)$ of MS specimens are listed in Tables 4(a) and 4 (b) respectively.

From Tables 4(a) and 4(b) it is clear that $R_{\mathrm{ct}}$ values are increased with increasing inhibitor concentration. The capacitance values $C_{\mathrm{dl}}$ decreases with inhibitor concentration and this decrease in $C_{\mathrm{dl}}$ is enhanced upon addition of $\mathrm{I}^{-}$ ions to the corrosive environment (inspect data listed in Tables 4(a) and 4(b)). These results suggest that the A9O3AP molecules function by adsorption at the metal/solution interface [30] and this adsorption is reinforced by $\mathrm{I}^{-}$ions. This decrease in $C_{\mathrm{dl}}$ may be explained on the basis that the double layer between the charged metal surface and the solution is considered as an electrical capacitor. The $\eta_{\mathrm{EIS} \%}$
TABLE 4: Electrochemical Impedance parameters of MS specimens in $0.5 \mathrm{M} \mathrm{H}_{2} \mathrm{SO}_{4}$ at $30^{\circ} \mathrm{C}$ in the absence and presence of inhibitor (a) and inhibitor $+0.2 \mathrm{mM} \mathrm{KI}$ (b).

(a)

\begin{tabular}{lccc}
\hline $\begin{array}{l}C \\
(\mathrm{mM})\end{array}$ & $\begin{array}{c}R_{\mathrm{ct}} \\
\left(\Omega \cdot \mathrm{cm}^{2}\right)\end{array}$ & $\begin{array}{c}C_{\mathrm{dl}} \\
\left(\mu \mathrm{F} \mathrm{cm}^{-2}\right)\end{array}$ & $\eta_{\mathrm{EIS} \%}$ \\
\hline 0 & 8.9 & 135 & - \\
0.2 & 10.9 & 103 & 18.35 \\
0.4 & 17.7 & 95.1 & 49.72 \\
0.6 & 21.1 & 94 & 57.82 \\
0.8 & 28.8 & 87 & 69.10 \\
1.0 & 38.6 & 75.8 & 76.94 \\
\hline
\end{tabular}

(b)

\begin{tabular}{lccc}
\hline $\begin{array}{l}C \\
(\mathrm{mM})\end{array}$ & $\begin{array}{c}R_{\mathrm{ct}} \\
\left(\Omega \cdot \mathrm{cm}^{2}\right)\end{array}$ & $\begin{array}{c}C_{\mathrm{dl}} \\
\left(\mu \mathrm{F} \mathrm{cm}^{-2}\right)\end{array}$ & $\eta_{\mathrm{EIS} \%}$ \\
\hline 0 & 8.9 & 135 & - \\
$0.2+\mathrm{KI}$ & 91 & 99.9 & 90.22 \\
$0.4+\mathrm{KI}$ & 102 & 93.7 & 91.27 \\
$0.6+\mathrm{KI}$ & 151 & 91.3 & 94.11 \\
$0.8+\mathrm{KI}$ & 198 & 79.7 & 95.51 \\
$1.0+\mathrm{KI}$ & 251 & 65.1 & 96.45 \\
\hline
\end{tabular}

data reveal that the corrosion inhibition capacity of A9O3AP is markedly enhanced by the addition of KI.

3.6. Potentiodynamic Polarization Studies. Potentiodynamic polarization curves for $\mathrm{A} 9 \mathrm{O} 3 \mathrm{AP}$ in $0.5 \mathrm{M} \mathrm{H}_{2} \mathrm{SO}_{4}$ at $30^{\circ} \mathrm{C}$ for MS specimens in the presence of various concentrations of inhibitor and inhibitor $+\mathrm{KI}$ are shown in Figures 8 and 9, respectively. Polarization parameters like corrosion current densities $\left(I_{\text {corr }}\right)$, corrosion potential $\left(E_{\text {corr }}\right)$, cathodic Tafel slope $\left(b_{c}\right)$, anodic Tafel slope $\left(b_{a}\right)$, and inhibition efficiency $\left(\eta_{\text {pol } \%}\right)$ for MS specimens are listed in Tables 5, and 6 respectively. The data show that, addition of the Schiff base to acid media affected both the cathodic and anodic parts of the curves. Addition of $\mathrm{I}^{-}$ions to $\mathrm{A} 9 \mathrm{O} 3 \mathrm{AP}-\mathrm{H}_{2} \mathrm{SO}_{4}$ systems results in marked decrease in the corrosion current density $\left(I_{\text {corr }}\right)$. In other words, both anodic and cathodic reactions are drastically inhibited. Generally if the shift of $E_{\text {corr }}$ is $>85$ with respect to $E_{\text {corr }}$ of uninhibited solution, the inhibitor can be viewed as either cathodic or anodic type $[22,31,32]$. In the present study the maximum shift of $E_{\text {corr }}$ is $19 \mathrm{mV}$, suggesting that $\mathrm{A} 9 \mathrm{O} 3 \mathrm{AP}$ acts as a mixed type inhibitor for MS specimens in $0.5 \mathrm{M} \mathrm{H}_{2} \mathrm{SO}_{4}$. From the values it is clear that the inhibition efficiency of A9O3AP alone is increased in presence of KI. These results also confirm the existence of strong synergism between A9O3AP and KI in the corrosion inhibition of MS in these solutions.

\section{Mechanism and Explanation for Synergism}

The synergistic inhibition brought about by the combination of A9O3AP and iodide ions for the corrosion of MS in $0.5 \mathrm{M}$ $\mathrm{H}_{2} \mathrm{SO}_{4}$ can be explained on the basis that halide ions have a 
TABLE 5: Potentiodynamic polarization parameters of $\mathrm{MS}$ specimens in $0.5 \mathrm{M} \mathrm{H}_{2} \mathrm{SO}_{4}$ at $30^{\circ} \mathrm{C}$ in the absence and presence of $\mathrm{A} 9 \mathrm{O} 3 \mathrm{AP}$.

\begin{tabular}{|c|c|c|c|c|c|}
\hline \multicolumn{6}{|c|}{ Tafel data } \\
\hline $\begin{array}{l}C \\
(\mathrm{mM}) \\
\end{array}$ & $\begin{array}{c}E_{\text {corr }} \\
(\mathrm{mV} / \mathrm{SCE})\end{array}$ & $\begin{array}{c}I_{\text {corr }} \\
\left(\mathrm{mA} / \mathrm{cm}^{2}\right)\end{array}$ & $\begin{array}{c}b_{a} \\
(\mathrm{mV} / \mathrm{dec})\end{array}$ & $\begin{array}{c}-b_{c} \\
(\mathrm{mV} / \mathrm{dec})\end{array}$ & $\eta_{\mathrm{pol} \%}$ \\
\hline Blank & -467 & 1.1700 & 82 & 124 & - \\
\hline 0.2 & -457 & 1.0220 & 95 & 114 & 12.65 \\
\hline 0.4 & -475 & 0.8240 & 78 & 116 & 29.57 \\
\hline 0.6 & -450 & 0.7010 & 68 & 117 & 40.09 \\
\hline 0.8 & -458 & 0.4511 & 63 & 103 & 61.44 \\
\hline 1.0 & -470 & 0.1730 & 57 & 097 & 85.21 \\
\hline
\end{tabular}

TABLE 6: Polarization parameters of MS specimens in $0.5 \mathrm{M} \mathrm{H}_{2} \mathrm{SO}_{4}$ at $30^{\circ} \mathrm{C}$ in the absence and presence of $\mathrm{A} 9 \mathrm{O} 3 \mathrm{AP}+0.2 \mathrm{mM} \mathrm{KI}$.

\begin{tabular}{|c|c|c|c|c|c|}
\hline \multicolumn{6}{|c|}{ Tafel data } \\
\hline $\begin{array}{l}C \\
(\mathrm{mM})\end{array}$ & $\begin{array}{c}E_{\text {corr }} \\
(\mathrm{mV} / \mathrm{SCE})\end{array}$ & $\begin{array}{c}I_{\text {corr }} \\
\left(\mathrm{mA} / \mathrm{cm}^{2}\right)\end{array}$ & $\begin{array}{c}b_{a} \\
(\mathrm{mV} / \mathrm{dec})\end{array}$ & $\begin{array}{c}-b_{c} \\
(\mathrm{mV} / \mathrm{dec})\end{array}$ & $\eta_{\text {pol\% }}$ \\
\hline Blank & -467 & 1.1700 & 82 & 124 & - \\
\hline $0.2+\mathrm{KI}$ & -469 & 0.1730 & 57 & 97 & 85.21 \\
\hline $0.4+\mathrm{KI}$ & -465 & 0.0980 & 63 & 102 & 91.62 \\
\hline $0.6+\mathrm{KI}$ & -470 & 0.0802 & 88 & 103 & 93.15 \\
\hline $0.8+\mathrm{KI}$ & -453 & 0.0401 & 30 & 99 & 96.57 \\
\hline $1.0+\mathrm{KI}$ & -451 & 0.0399 & 40 & 130 & 96.59 \\
\hline
\end{tabular}

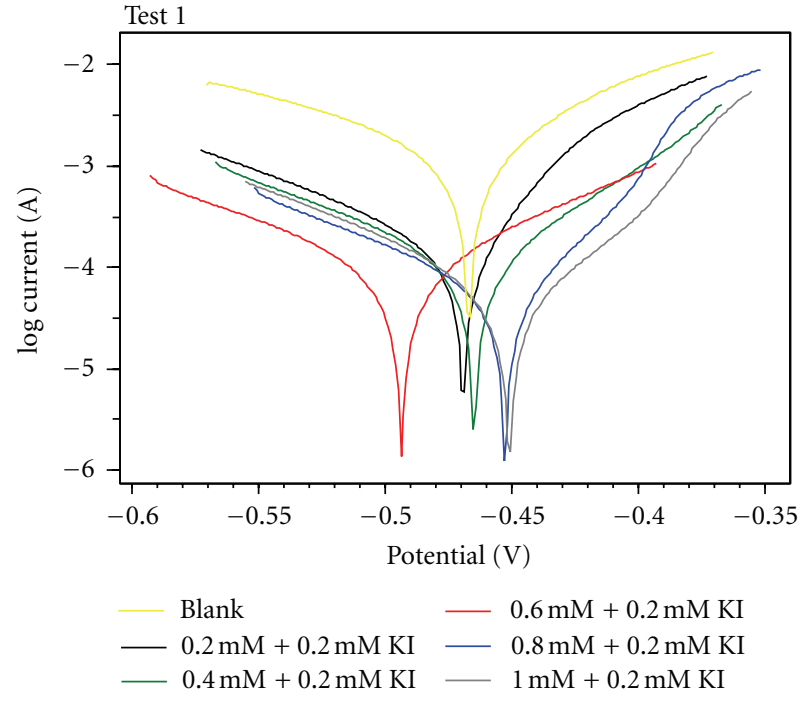

Figure 9: Tafel plots of MS specimens in $0.5 \mathrm{M} \mathrm{H}_{2} \mathrm{SO}_{4}$ at $30^{\circ} \mathrm{C}$, with and without inhibitor $+\mathrm{KI}$.

greater tendency to be adsorbed on the surface in attraction with organic cations. The protonated Schiff base $\left(\mathrm{A} \mathrm{O} 3 \mathrm{AP}^{+}\right)$ is then adsorbed by coulombic attraction at the steel surface, where iodide ions are already adsorbed by chemisorptions (Figure 10). Greater surface coverage from the stabilization of adsorbed iodide ions by means of electrostatic interaction with $\mathrm{A} 9 \mathrm{O} 3 \mathrm{AP}^{+}$facilitates corrosion inhibition synergism. $\mathrm{I}^{-}$ alone polarizes both the anodic and cathodic reaction of iron over a wide potential range. It is apparent then that the effects of $\mathrm{I}^{-}$are not due to electrostatic effects alone, but

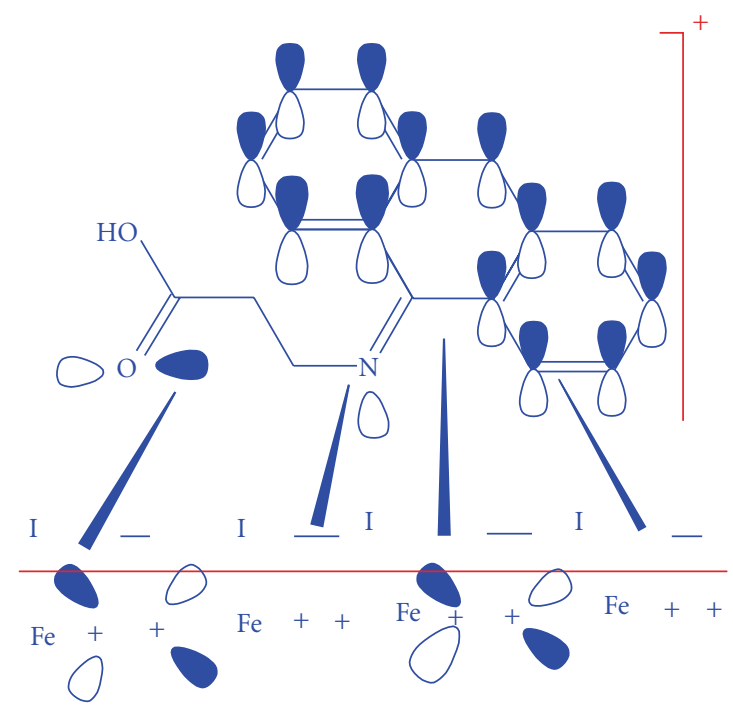

FIGURE 10: The schematic illustration of modes of adsorption on mild steel in $0.5 \mathrm{M} \mathrm{H}_{2} \mathrm{SO}_{4}$.

some covalent bonding to the metal must be involved. The large size and ease of polarizability of $\mathrm{I}^{-}$facilitate electron pair bonding. The halide ions are first adsorbed on the metal surface and the inhibitor is then drawn in to the double layer by the adsorbed halide ion, such that the ion pair formation occurs directly on the metal surface:

$$
\begin{gathered}
A_{s} \longrightarrow A_{\mathrm{ads}}, \\
B_{s}+A_{\mathrm{ads}} \longrightarrow(B A)_{\mathrm{ads}},
\end{gathered}
$$


where $B s$ and $A s$ represent inhibitor and halide, ion respectively, in the bulk solution, while $A_{\mathrm{ads}}$ and $(B A)_{\text {ads }}$ refers halide ion and ion-pair, respectively, in the adsorbed state.

\section{Conclusions}

(1) A9O3AP acts as moderate inhibitor for MS in $0.5 \mathrm{M}$ sulphuric acid medium.

(2) Inhibition efficiency increases with increase in concentration of inhibitor.

(3) The addition of iodide ions to A9O3AP enhanced the inhibition efficiency due to synergistic effect.

(4) The adsorption of A9O3AP alone and in combination with iodide ions obeys Freundlich and Langmiur adsorption isotherms, respectively.

(5) The thermodynamic parameters calculated from the adsorption isotherms showed that both physisorption and chemisorption are involved in the inhibition process.

\section{References}

[1] O. James, N. C. Oforka, and O. K. Abiola, "Inhibition of acid corrosion of mild steel by pyridoxal and pyridoxol hydrochlorides," International Journal of Electrochemical Science, vol. 2, pp. 278-284, 2007.

[2] S. A. Abd El-Maksoud, "The effect of organic compounds on the electrochemical behaviour of steel in acidic media. A review," International Journal of Electrochemical Science, vol. 3, pp. 528-555, 2008.

[3] E. E. Ebenso, P. C. Okafor, O. E. Offiong, B. I. Ita, U. J. Ibok, and U. J. Ekpe, "Comparative investigation into the kinetics of corrosion inhibition of aluminium alloy AA 1060 in acidic medium," Bulletin of Electrochemistry, vol. 17, no. 10, pp. 459464, 2001.

[4] T. A. Sethi, R. K. Chaturvedi, Upadyay, and S. P. Marthur, "Corrosion inhibitory effects of some Schiff's bases on mild steel in acid media," Journal of the Chilean Chemical Society, vol. 52, no. 3, pp. 1206-1213, 2007.

[5] K. P. Srivastva, A. Kumar, and R. Singh, "Bivalent transition metal complexes of tridentate Schiff base ligands: an ecofriendly study," Journal of Chemical and Pharmaceutical Research, vol. 2, no. 6, pp. 68-77, 2010.

[6] S. B. Ade, M. N. Deshpande, and D. G. Kolhatkar, "Corrosion a universal environmental problem: a role of Schiff base metal complexes as inhibitors," Journal of Chemical and Pharmaceutical Research, vol. 4, no. 2, pp. 1033-1035, 2012.

[7] A. Paul, K. J. Thomas, V. P. Raphael, and K. S. Shaju, "Electrochemical and Gravimetric corrosion Inhibition Investigations of A Heterocyclic Schiff Base Derived From 3-Formylindole," IOSR Journalof Applied Chemistry (IOSRJAC) , vol. 1, pp. 1723, 2012.

[8] E. E. Ebenso, H. Alemu, S. A. Umoren, and I. B. Obot, "Inhibition of mild steel corrosion in sulphuric acid using alizarin yellow GG dye and synergistic iodide additive," International Journal of Electrochemical Science, vol. 3, pp. 1325-1339, 2008.

[9] S. A. Umoren, U. M. Eduok, and E. E. Oguzie, "Corrosion inhibition of mild steel in $1 \mathrm{M} \mathrm{H}_{2} \mathrm{SO}_{2}$ by polyvinyl pyrrolidone and synergistic iodide additives," Portugaliae Electrochimica Acta, vol. 26, no. 6, pp. 533-546, 2008.

[10] F. Bentiss, M. Bouanis, B. Mernari, M. Traisnel, and M. Lagrenee, "Effect of iodide ions on corrosion inhibition of mild steel by 3,5-bis(4-methylthiophenyl)-4H-1,2,4-triazole in sulfuric acid solution," Journal of Applied Electrochemistry, vol. 32, no. 6, pp. 671-678, 2002.

[11] M. A. Quraishi and J. Rawat, "Influence of iodide ions on inhibitive performance of tetraphenyl-dithia-octaazacyclotetradeca-hexaene (PTAT) during pickling of mild steel in hot sulfuric acid," Materials Chemistry and Physics, vol. 70, no. 1, pp. 95-99, 2001.

[12] Z. A. Iofa, V. V. Batrakov, and Cho-Ngok-Ba, "Influence of anion adsorption on the action of inhibitors on the acid corrosion of iron and cobalt," Electrochimica Acta, vol. 9, no. 12, pp. 1645-1653, 1964.

[13] I. F. Fishtik, I. I. Vatman, and F. A. Spatar, "The mechanism of ion-pair formation in the inner part of the double layer," Journal of Electroanalytical Chemistry, vol. 165, no. 1-2, pp. 18, 1984.

[14] S. Deng, X. Li, and H. Fu, "Synergistic inhibition effect of 6benzylaminopurine and iodide ion on the corrosion of cold rolled steel in H3PO4 solution," CorrosionScience, vol. 53, pp. 3704-3711, 2011.

[15] ASTM, "Standard recommended practice for the laboratory immersion corrosion testing of metals," Tech. Rep. ASTM G31-72, ASTM, Philadelphia, Pa, USA, 1990.

[16] K. C. Emregul and O. Atakol, "Corrosion inhibition of iron in $1 \mathrm{M} \mathrm{HCl}$ solution with Schiff base compounds and derivatives," Materials Chemistry and Physics, vol. 83, no. 2-3, pp. 373-379, 2004.

[17] A. Raman and P. Labine, Reviews on Corrosion Inhibitor Science and Technology, NACE, Houston, Tex, USA, 1986.

[18] H. Ashassi-Sorkhabi, B. Shaabani, and D. Seifzadeh, "Effect of some pyrimidinic Shciff bases on the corrosion of mild steel in hydrochloric acid solution," Electrochimica Acta, vol. 50, no. 16-17, pp. 3446-3452, 2005.

[19] M. Bouklah, B. Hammouti, M. Lagrenée, and F. Bentiss, "Thermodynamic properties of 2,5-bis(4-methoxyphenyl)1,3,4-oxadiazole as a corrosion inhibitor for mild steel in normal sulfuric acid medium," Corrosion Science, vol. 48, no. 9, pp. 2831-2842, 2006.

[20] E. Cano, J. L. Polo, A. L. A. Iglesia, and J. M. Bastidas, "A study on the adsorption of benzotriazole on copper in hydrochloric acid using the inflection point of the isotherm," Adsorption, vol. 10, no. 3, pp. 219-225, 2004.

[21] F. Bentiss, M. Lebrini, and M. Lagrenée, "Thermodynamic characterization of metal dissolution and inhibitor adsorption processes in mild steel/2,5-bis(n-thienyl)-1,3,4-thiadiazoles/ hydrochloric acid system," Corrosion Science, vol. 47, no. 12, pp. 2915-2931, 2005.

[22] W. H. Li, Q. He, S. T. Zhang, C. L. Pei, and B. R. Hou, "Some new triazole derivatives as inhibitors for mild steel corrosion in acidic medium," Journal of Applied Electrochemistry, vol. 38, no. 3, pp. 289-295, 2008.

[23] K. Aramaki and M. Hackerman, "Inhibition mechanism of medium-sized polymethyleneimine," Journal of The Electrochemical Society, vol. 116, no. 5, pp. 568-574, 1969.

[24] N. Caliskan and S. Bilgic, "Effect of iodide ions on the synergistic inhibition of the corrosion of manganese-14 steel in acidic media," Applied Surface Science, vol. 153, no. 2-3, pp. 128-133, 2000. 
[25] A. R. S. Priya, V. S. Muralidharam, and A. Subramannia, "Development of novel acidizing inhibitors for carbon steel corrosion in $15 \%$ boiling hydrochloric acid," Corrosion, vol. 64, no. 6, pp. 541-552, 2008.

[26] M. El Azhar, B. Mernari, M. Traisnel, F. Bentiss, and M. Lagrenée, "Corrosion inhibition of mild steel by the new class of inhibitors [2,5-bis(n-pyridyl)-1,3,4-thiadiazoles] in acidic media," Corrosion Science, vol. 43, no. 12, pp. 2229-2238, 2001.

[27] A. Yurt, A. Balaban, S. U. Kandemir, G. Bereket, and B. Erk, "Investigation on some Schiff bases as $\mathrm{HCl}$ corrosion inhibitors for carbon steel," Materials Chemistry and Physics, vol. 85, no. 2-3, pp. 420-426, 2004.

[28] J. R. Macdonald, W. B. Johnson, and J. R. Macdonald, Theory in Impedance Spectroscopy, John Wiley \& Sons, New York, NY, USA, 1987.

[29] A. K. Singh, S. K. Shukla, M. Singh, and M. A. Quraishi, "Inhibitive effect of ceftazidime on corrosion of mild steel in hydrochloric acid solution," Materials Chemistry and Physics, vol. 129, no. 1-2, pp. 68-76, 2011.

[30] M. MaCafferty and N. Hackerman, "Double layer capacitance of iron and corrosion inhibition with polymethylene diamines," Journal of The Electrochemical Society, vol. 119, no. 2, pp. 146-154, 1972.

[31] X. Li, S. Deng, and H. Fu, "Synergism between red tetrazolium and uracil on the corrosion of cold rolled steel in $\mathrm{H}_{2} \mathrm{SO}_{4}$ solution," Corrosion Science, vol. 51, no. 6, pp. 1344-1355, 2009.

[32] E. S. Ferreira, C. Giacomelli, F. C. Giacomelli, and A. Spinelli, "Evaluation of the inhibitor effect of L-ascorbic acid on the corrosion of mild steel," Materials Chemistry and Physics, vol. 83, no. 1, pp. 129-134, 2004. 

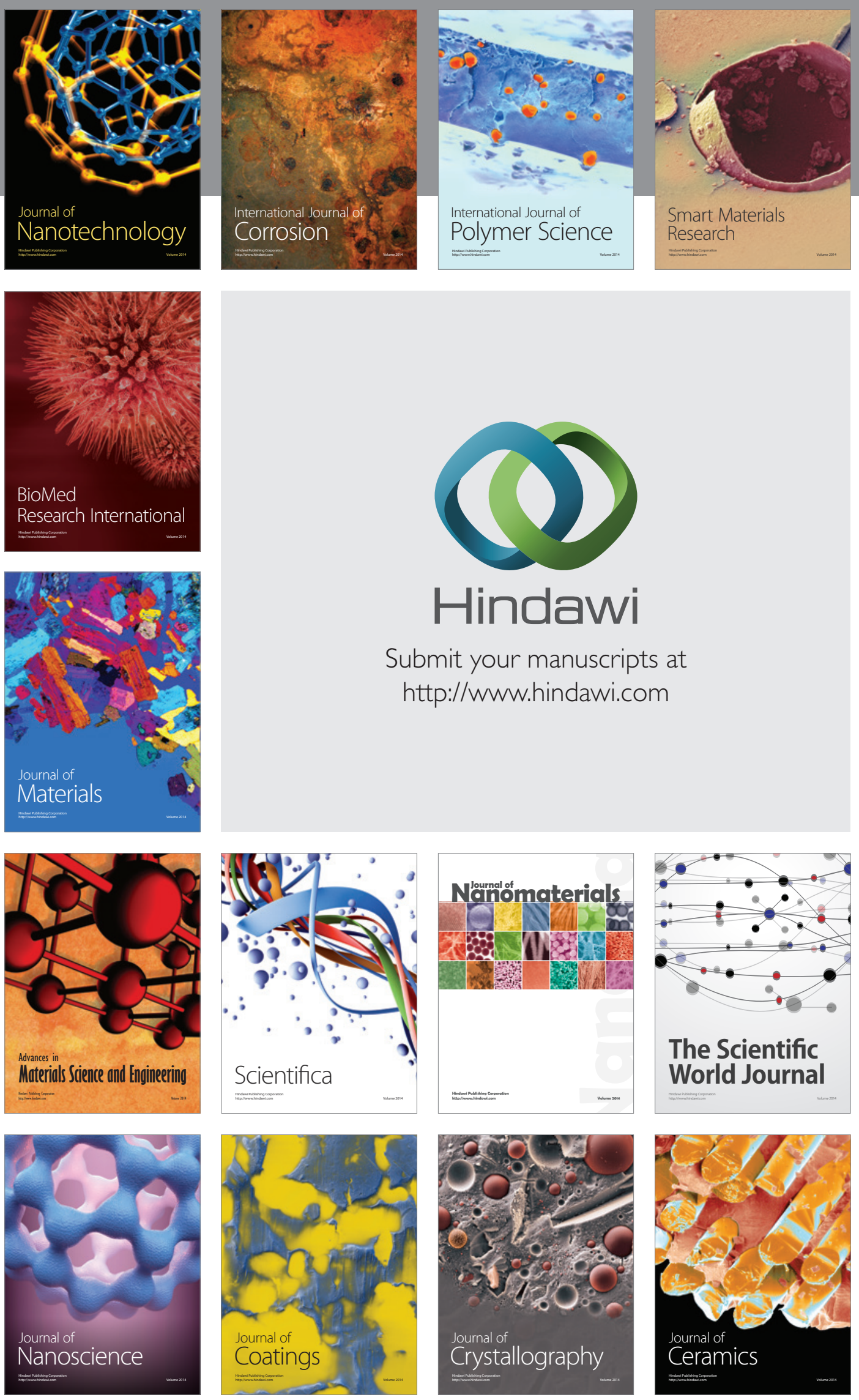

The Scientific World Journal

Submit your manuscripts at

http://www.hindawi.com

\section{World Journal}

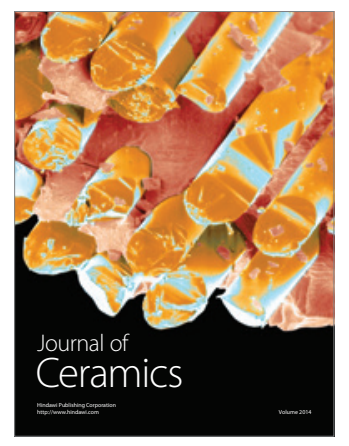

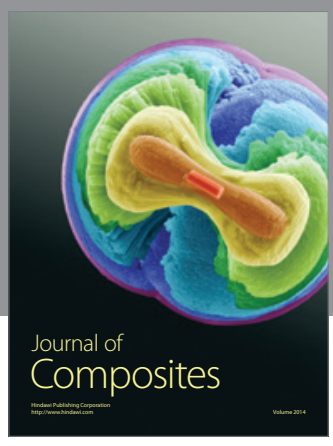
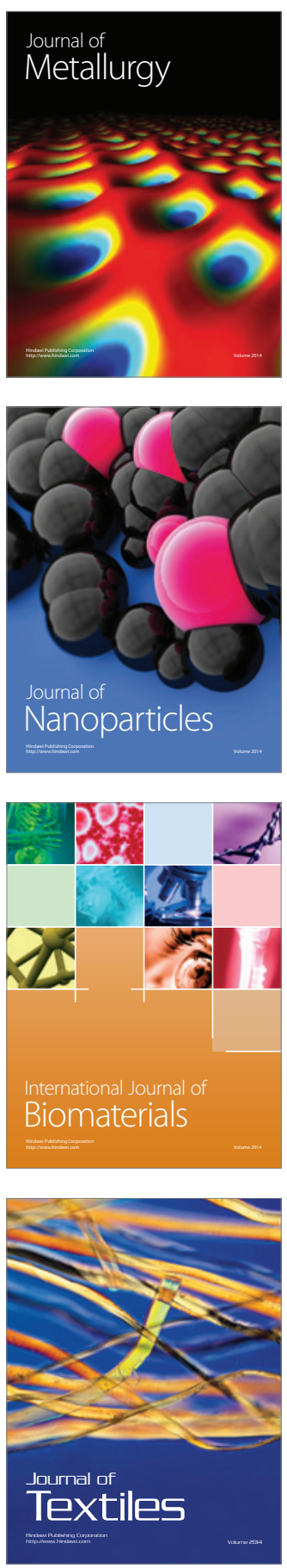